\title{
Erratum
}

\section{Experimental Investigation into the Tractive Prerolling Behavior of Balls in V-Grooved Tracks}

\author{
Kris De Moerlooze and Farid Al-Bender \\ Mechanical Engineering Department, Division Production Engineering, Machine design and Automation, \\ Katholieke Universiteit Leuven, Celestijnenlaan 300B, BE-3001 Heverlee, Belgium \\ Correspondence should be addressed to Farid Al-Bender, farid.al-bender@mech.kuleuven.be \\ Received 2 October 2008; Accepted 19 October 2008
}

Copyright (c) 2008 K. De Moerlooze and F. Al-Bender. This is an open access article distributed under the Creative Commons Attribution License, which permits unrestricted use, distribution, and reproduction in any medium, provided the original work is properly cited.

(1) In [1, equation (15), page 6],

$$
\left(p_{x}, p_{y}\right)=L(u, v)
$$

should be replaced by

$$
\left(p_{x}, p_{y}\right)=\frac{1}{L}(u, v)
$$

(2) In [1, equation (16), page 6],

$$
(u, v)_{\text {new }}=\frac{\mu p_{z}}{L}\left(\frac{(u, v)}{\|(u, v)\|}\right)_{\text {old }}
$$

should be replaced by

$$
(u, v)_{\text {new }}=\mu p_{z} L\left(\frac{(u, v)}{\|(u, v)\|}\right)_{\text {old }} .
$$

\section{REFERENCES}

[1] Kris De Moerlooze and Farid Al-Bender, "Experimental investigation into the tractive prerolling behavior of balls in $\mathrm{V}$-grooved tracks," Advances in Tribology, vol. 2008, Article ID 561280, 10 pages, 2008. 

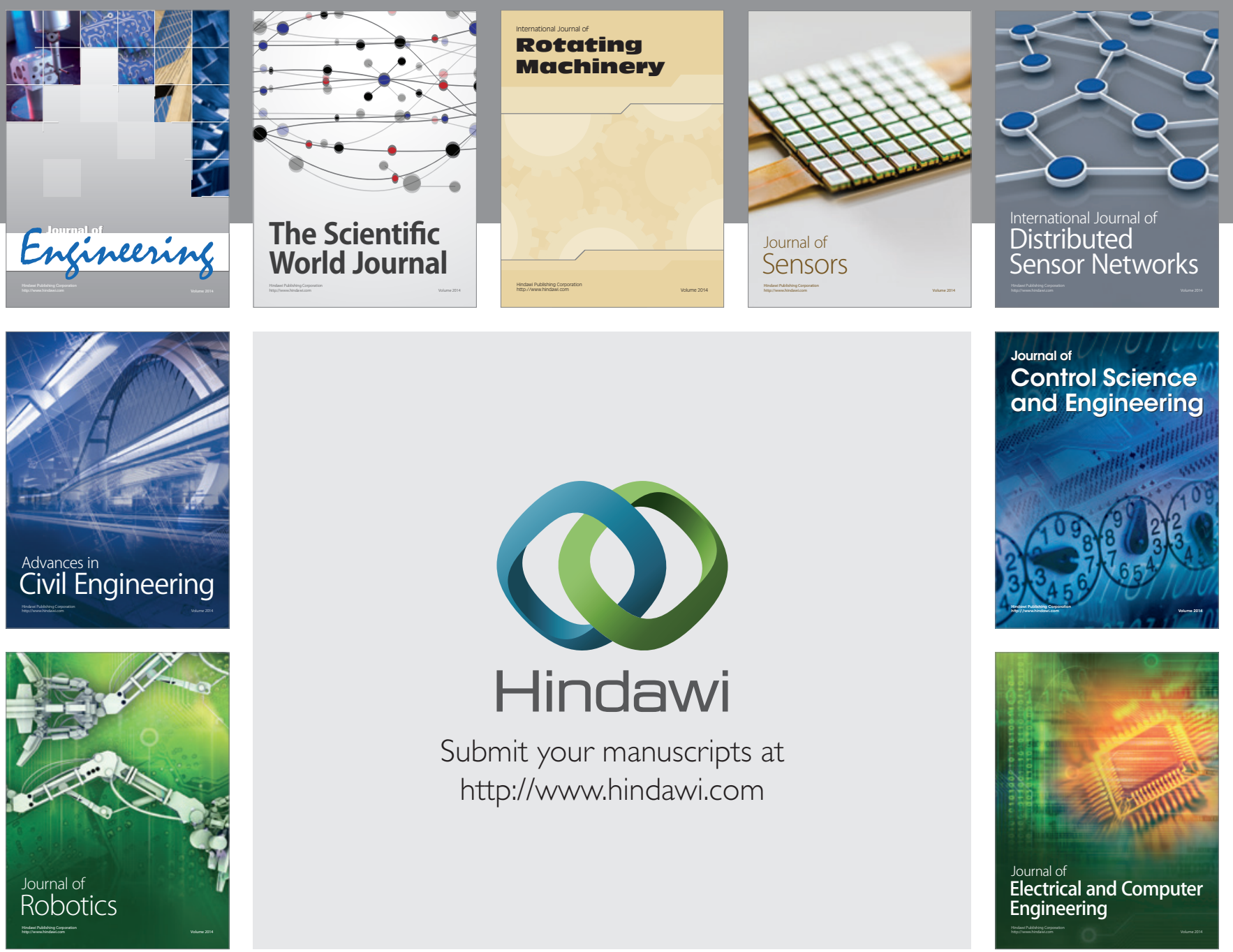

Submit your manuscripts at

http://www.hindawi.com
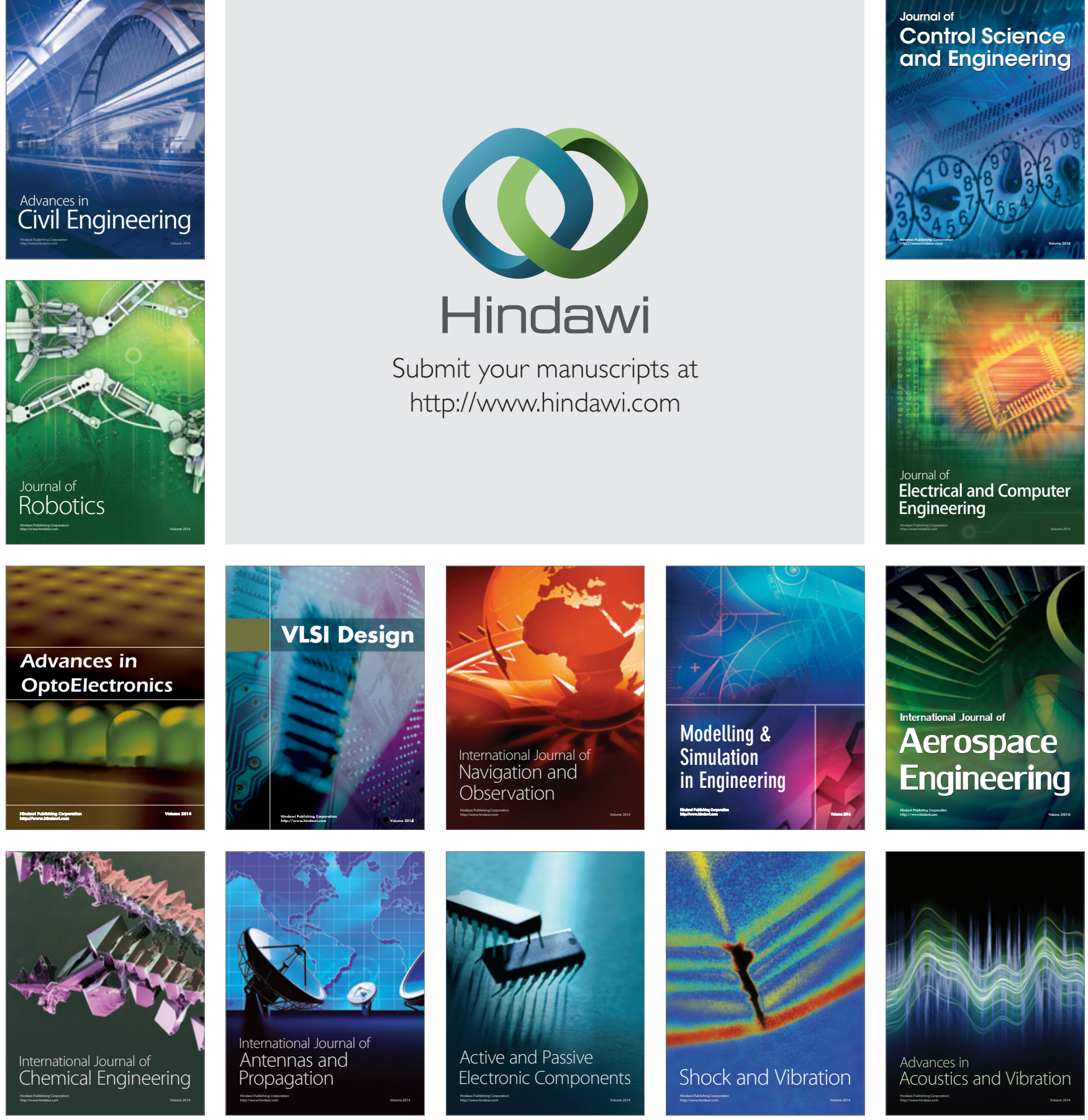